\title{
Remote sensing of water vapour profiles in the framework of the Total Carbon Column Observing Network (TCCON)
}

\author{
M. Schneider ${ }^{1,2}$, E. Sepúlveda ${ }^{3,1}$, O. García ${ }^{1}$, F. Hase ${ }^{2}$, and T. Blumenstock ${ }^{2}$ \\ ${ }^{1}$ Agencia Estatal de Meteorología (AEMET), CIAI, Santa Cruz de Tenerife, Spain \\ ${ }^{2}$ Karlsruhe Institute of Technology (KIT), IMK-ASF, Karlsruhe, Germany \\ ${ }^{3}$ University of La Laguna, Santa Cruz de Tenerife, Spain
}

Received: 15 July 2010 - Published in Atmos. Meas. Tech. Discuss.: 31 August 2010

Revised: 19 December 2010 - Accepted: 20 December 2010 - Published: 22 December 2010

\begin{abstract}
We show that the near infrared solar absorption spectra recorded in the framework of the Total Carbon Column Observing Network (TCCON) can be used to derive the vertical distribution of tropospheric water vapour. The resolution of the TCCON spectra of $0.02 \mathrm{~cm}^{-1}$ is sufficient for retrieving lower and middle/upper tropospheric water vapour concentrations with a vertical resolution of about 3 and $8 \mathrm{~km}$, respectively. We document the good quality of the remotely-sensed profiles by comparisons with coincident in-situ Vaisala RS92 radiosonde measurements. Due to the high measurement frequency, the TCCON water vapour profile data offer novel opportunities for estimating the water vapour variability at different timescales and altitudes.
\end{abstract}

\section{Introduction}

During the last years large investments have been undertaken to set up the Total Carbon Column Observing Network (TCCON, www.tccon.caltech.edu, Wunch et al., 2010a) as a quasi-automated monitoring network. A TCCON experiment consists of a high precision solar tracker and a high quality ground-based Fourier Transform Infrared (FTIR) spectrometer (e.g., Geibel et al., 2010). A big shipping container is typically used as housing of the equipment whose overall material costs are about $500 \mathrm{kEUR}$. In the meanwhile there are about 15 globally-distributed FTIR experiments operating in the framework of the TCCON. The experiments record direct solar spectra in the near-infrared spectral region $\left(4000-9000 \mathrm{~cm}^{-1}\right)$. In this spectral region there are distinct

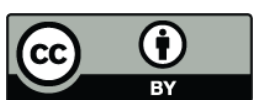

Correspondence to: $\mathrm{M}$. Schneider (matthias.schneider@kit.edu) rotational-vibrational bands of the atmospheric trace gases $\mathrm{CO}_{2}, \mathrm{CH}_{4}, \mathrm{~N}_{2} \mathrm{O}, \mathrm{HF}, \mathrm{CO}, \mathrm{H}_{2} \mathrm{O}$, and HDO. The TCCON will focus on the measurement of accurate and precise total column abundances of the greenhouse gases $\mathrm{CO}_{2}, \mathrm{CH}_{4}$, and $\mathrm{N}_{2} \mathrm{O}$ (e.g., Yang et al., 2002; Washenfelder et al., 2006; Wunch et al., 2010b). Concerning $\mathrm{CO}_{2}$ a precision of 0.1$0.2 \%(0.4-0.8 \mathrm{ppm})$ is targeted. Achieving such high precision is essential for using the column-averaged data in carbon cycle research (Olsen and Randerson, 2004) however, it is a very challenging task.

In this context there have been large efforts to ensure that the TCCON experiments produce spectra of very high quality: (1) At almost all sites very stable FTIR spectrometer are applied (Bruker IFS 125HR) and the instrumental line shape (ILS) is characterised routinely (Hase et al., 1999). (2) A DC-correction is applied on the interferogram, which avoids artificial baseline offsets caused by intensity fluctuations while scanning (Keppel-Aleks et al., 2007). (3) Detector nonlinearities - which cause baseline offsets - are corrected (Abrams et al., 1994). (4) The sampling accuracy is optimised in order to avoid ghosts (Messerschmidt et al., 2010). (5) A very high quality solar tracking system has been developed (Gisi et al., 2010). It guarantees a very high quality of the measurements, also for low solar elevation angles.

TCCON will provide solar absorption spectra of highest quality, at several globally distributed sites, and for many years, which makes it very attractive for many fields of atmospheric research. Water vapour is a key parameter concerning climate variability and climate feedbacks (Randall et al., 2007; Sherwood et al., 2010) whereby long-term observations of middle/upper tropospheric water vapour are particularly interesting for climate research, since at these altitudes water vapour acts very effectively as greenhouse gas (Spencer and Braswell, 1997). TCCON's demanding quality

Published by Copernicus Publications on behalf of the European Geosciences Union. 
requirements and its long-term strategy are very promising for studying the atmospheric water vapour distribution and its interaction with climate change, but it is important to document the quality and characteristics of the water vapour data that can be produced by the TCCON. In addition precise TCCON water vapour retrievals are important for ensuring a high quality of the TCCON's prime target gases $\left(\mathrm{CO}_{2}\right.$, $\mathrm{CH}_{4}$, and $\mathrm{N}_{2} \mathrm{O}$ ). Since the highly variable water vapour absorption signatures often interfere with signatures of the other TCCON absorbers a precise estimation of the actual atmospheric $\mathrm{H}_{2} \mathrm{O}$ distribution for each individual spectra is needed in order to avoid significant interference errors.

Ground-based solar absorption spectra measured in the middle infrared in the framework of the Network for the Detection of Atmospheric Composition Change (NDACC, Kurylo and Zander, 2000, www.acd.ucar.edu/irwg) allow the remote sensing of tropospheric water vapour profiles (Schneider et al., 2006; Schneider and Hase, 2009; Schneider et al., 2010a). More recently, Schneider et al. (2010c) show that the water vapour profiles retrieved from near infrared signatures $\left(4500-4700 \mathrm{~cm}^{-1}\right)$ are also of very good quality. However, the so far applied spectra have been highly-resolved (spectral resolution of $0.0025-0.0075 \mathrm{~cm}^{-1}$ ), whereas the resolution of the TCCON spectra is limited to $0.02 \mathrm{~cm}^{-1}$. In this paper we use TCCON spectra measured at the Izaña Observatory (Tenerife Island, Spain, $28^{\circ} 18^{\prime} \mathrm{N}, 16^{\circ} 29^{\prime} \mathrm{W}$ at $2370 \mathrm{~m}$ a.s.l.) and show that the TCCON spectral resolution is still sufficient to derive tropospheric water vapour profiles. Since a lower resolution spectrum is measured within $1-2 \mathrm{~min}$ the TCCON can provide free tropospheric water vapour data with an unprecedented high measurement frequency. In Sect. 2 we briefly describe the measurement principle of the TCCON and the generalities of evaluating high resolution solar absorption spectra and the setup of the water vapour profile retrieval. Sections 3-5 characterise and validate the profiles and Sect. 6 demonstrates the unique measurement frequency of the TC$\mathrm{CON}$ water vapour profiles. The paper ends with a summary (Sect. 7).

\section{A TCCON experiment and the principles of ground-based infrared remote sensing}

Figure 1 shows the two main components of a TCCON experiment: a precise solar tracker (left photograph) that captures the direct solar light beam and a high resolution FTIR spectrometer (right photograph). For TCCON the FTIR spectrometer measures in the $4000-9000 \mathrm{~cm}^{-1}$ region with a resolution of $0.02 \mathrm{~cm}^{-1}$ (i.e., maximum optical path difference, $\mathrm{OPD}$, of $45 \mathrm{~cm}$ ). This corresponds to a resolution power $\lambda / \Delta \lambda$ at $5000 \mathrm{~cm}^{-1}$ of approx. $2.5 \times 10^{5}$. Recording of one spectrum requires between 30 seconds and a few minutes, depending on the quality needed: one scan can be performed in $3 \mathrm{~s}$, but often several scans are co-added in or-

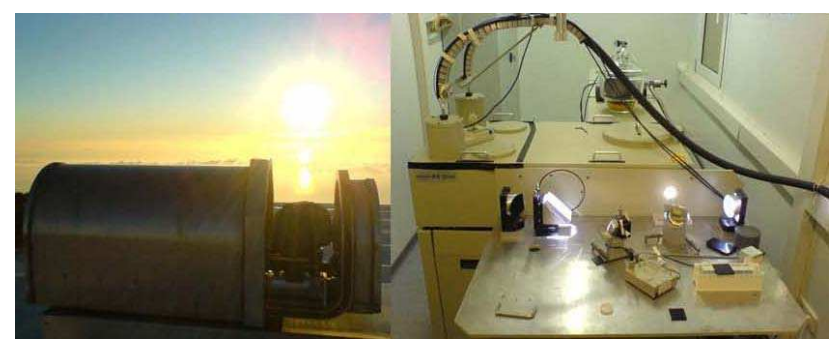

Fig. 1. The TCCON experiment at the Izaña Atmospheric Research Centre. The solar tracker (left photograph) is situated at the top of the experimental housing. It collects the direct solar beam and reflects it into the housing of the FTIR spectrometer (right photograph) where it is coupled into the spectrometer (circular light spot on the right part of the photograph).

der to increase the signal to noise ratio. Together with the AC-signal, the DC-signal of the interferogram is recorded. This allows correcting for inhomogeneous sky conditions, like cirrus cloud cover (Keppel-Aleks et al., 2007). No observations can be performed for a sky covered with optically thick clouds.

The basic equation for analysing near infrared solar absorption spectra is Lambert Beer's law:

$I(\lambda)=I_{\text {sun }}(\lambda) \exp \left(-\int_{\text {TOA }}^{\text {Obs. }} \sigma_{x}(\lambda, s(T, p)) x(s) d s\right)$

Here $I(\lambda)$ is the measured intensity at wavelength $\lambda, I_{\text {sun }}$ the solar intensity, $\sigma_{x}(\lambda, s)$ is the absorption cross section and $x(s)$ the concentration of an absorber $x$ at location $s$. The integration is performed along the path of the direct sunlight (from the top of the atmosphere (TOA) to the observer). The cross section $\sigma_{x}$ depends on temperature and pressure. The measurement $I(\lambda)$ is simulated by a precise line-by-line radiative transfer model, which includes a ray tracing module (e.g., Hase and Höpfner, 1999) in order to determine how the solar light passes through the different atmospheric layers.

By means of the discretisation we can describe the vertical distribution of the absorber in form of a vector $\boldsymbol{x}(z)$ (amount of the absorber $x$ at level $z$ ). If we also describe the simulated spectrum, $I(\lambda)$, in form of a vector $\boldsymbol{y}$ containing the radiances in the different spectral bins, we can define a forward relation, $F$, that connects the solar absorption spectrum $(y)$ to the vertical distribution of the absorber $(x)$, to parameters describing the atmospheric state $\left(\boldsymbol{p}_{\text {atmos }}\right)$, and to parameters describing the measurement system $\left(\boldsymbol{p}_{\exp }\right)$ :

$\boldsymbol{y}=\boldsymbol{F}\left(\boldsymbol{x}, \boldsymbol{p}_{\text {atmos }}, \boldsymbol{p}_{\exp }\right)$

$\boldsymbol{F}$ is a vector valued function which simulates the atmospheric radiative transfer and the characteristics of the measurement system (spectral resolution, instrumental line shape, etc.). The retrieval consists in adjusting the amount of the absorber so that simulated and measured spectrum agree. This is a non-linear problem (see Eq. 1) and the 


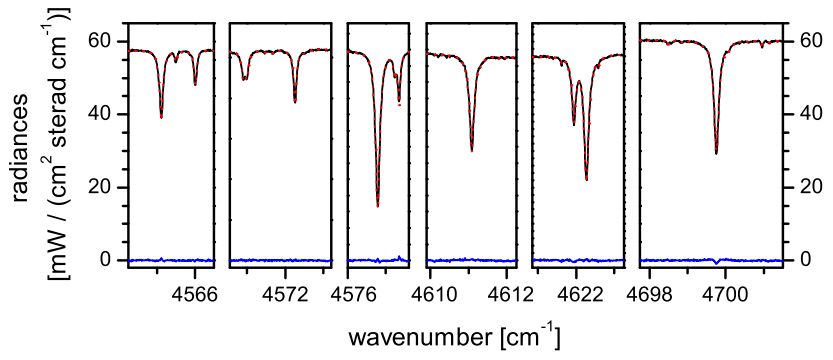

Fig. 2. The used spectral microwindows with $\mathrm{H}_{2} \mathrm{O}$ signatures. The shown measurement was taken on the 31st of March 2010, at a solar elevation of $43.4^{\circ}$, and for a total water vapour column amount of $4.7 \mathrm{~mm}$. Black line: measured spectrum; Red line: simulated spectrum; Blue line: residuals (difference between measurement and simulation).

solution is obtained by iterative calculations. For each iteration the derivatives $\partial y / \partial x$ determine the changes in the spectral fluxes $\boldsymbol{y}$ for changes in the vertical distribution of the absorber $\boldsymbol{x}$. These derivatives are sampled in a Jacobian matrix $\mathbf{K}$ :

$\partial y=\mathbf{K} \partial x$

Inverting $\mathbf{K}$ of Eq. 3 would allow an iterative calculation of the sought variables $\boldsymbol{x}$, but the problem is under-determined, i.e., the columns of $\mathbf{K}$ are not linearly independent and there are many different solutions that are in acceptable agreement with the measurement. We cannot derive a unique solution but we can estimate the most probable solution for the given measurement. This optimal estimation (OE) approach combines the measurement information with a priori knowledge and provides the most probable solution by minimising the following cost function:

$[\boldsymbol{y}-\boldsymbol{F}(\boldsymbol{x})]^{T} \mathbf{S}_{\epsilon}{ }^{-1}[\boldsymbol{y}-\boldsymbol{F}(\boldsymbol{x})]+\left[\boldsymbol{x}-\boldsymbol{x}_{a}\right]^{T} \mathbf{S}_{\mathbf{a}}{ }^{-1}\left[\boldsymbol{x}-\boldsymbol{x}_{a}\right]$

Where $\mathbf{S}_{\epsilon}$ is the noise covariance, $\boldsymbol{x}_{\boldsymbol{a}}$ and $\mathbf{S}_{\mathbf{a}}$ are the a-priori known mean distribution and the covariance of the distribution of the absorber, respectively. The a priori water vapour information is deduced from daily Vaisala RS92 radiosondes, which have been launched since 2005 just about $15 \mathrm{~km}$ southeast of the Izaña Observatory. For more details about $\mathrm{OE}$ approaches please refer to the textbook of C. D. Rodgers (Rodgers, 2000).

The optimal estimation of atmospheric water vapour amounts from ground-based FTIR spectra is far from being a typical atmospheric inversion problem and, due to its large vertical gradient and variability, standard retrieval methods are not appropriate. Only very recently the ground-based infrared remote sensing of water vapour profiles has become feasible. Among others, it requires the inversion to be performed on a logarithmic scale (Schneider et al., 2006) and the application of a speed dependent Voigt line shape model (Schneider et al., 2011, and references therein). We use the code PROFFIT (Hase et al., 2004), which comprises all the retrieval options that are required for ground-based water vapour profile analyses (for a review please refer to Schneider and Hase, 2009).

For the near infrared water vapour retrieval we fit the spectral microwindows as depicted in Fig. 2. In addition to the water vapour lines these spectral windows contain weak absorption signatures of $\mathrm{CO}_{2}, \mathrm{~N}_{2} \mathrm{O}$, and $\mathrm{CH}_{4}$. All these absorbers are jointly fitted. For our spectral line-byline simulations we apply the HITRAN 2008 (Rothman et al., 2009) spectroscopic line parameters which we adjusted for a speed-dependent Voigt line shape model (Schneider et al., 2011). As temperature profile we apply the National Centers for Environmental Prediction (NCEP) 12:00 UT reanalysis temperatures.

\section{Water vapour profile error analyses}

Our assumed uncertainty sources are given in Table 1. Major efforts have been undertaken for constraining the instrumental uncertainties of a TCCON experiment (Abrams et al., 1994; Hase et al., 1999; Keppel-Aleks et al., 2007; Messerschmidt et al., 2010; Gisi et al., 2010). As remaining instrumental uncertainties we assume a measurement noise and baseline offset of $0.1 \%$ (noise-to-signal and offset-to-signal, respectively), a modulation efficiency of $5 \%$ per $100 \mathrm{~cm}$ optical path difference (OPD), a phase error of $0.01 \mathrm{rad}$, and a line of sight (LOS) uncertainty of $1^{\prime}$.

In addition there are uncertainties in the applied 12:00 UT NCEP reanalysis temperature profiles and the spectroscopic line parameters. We assume uncorrelated temperature uncertainty of $2 \mathrm{~K}$ for the lower troposphere (below $5 \mathrm{~km}$ ) as well as $2 \mathrm{~K}$ for the upper troposphere (above $5 \mathrm{~km}$ ). These uncertainties might be caused by errors in the NCEP data or by diurnal cycles (the applied NCEP data is for 12:00 UT, whereas Izaña's FTIR measurements are performed between 10 and 18:00 UT). As uncertainties in the line strength $(S)$ and pressure broadening parameter $\left(\gamma_{\text {air }}\right)$ we assume $1 \%$ and for the strength of the speed-dependence $\left(\Gamma_{2} / \Gamma_{0}\right.$, Wagner and Birk, 2009; Schneider et al., 2011) we assume 5\%. Please note that uncertainties in the spectroscopic parameters - although being systematic - can produce random errors, since the effect of the errors depends on the sensitivity of the remote sensing system which, for example, differs for dry and wet atmospheric conditions.

The error estimation method is the same as described in Schneider et al. (2010c), which should be consulted for more details. In Figs. 3 and 4 we depict the estimated random and systematic errors for the retrieved profiles. We perform the estimations for very high resolution spectra (spectral resolution of $0.004 \mathrm{~cm}^{-1}$ typically used in NDACC) and for spectra with TCCON resolution $\left(0.02 \mathrm{~cm}^{-1}\right)$. Uncertainties in the ILS, the applied temperatures, and the spectroscopic parameters are the leading error sources. In addition to the 
Table 1. Assumed experimental and temperature random uncertainty.

\begin{tabular}{ll}
\hline source & uncertainty \\
\hline measurement noise & $0.1 \%$ \\
baseline offset & $0.1 \%$ \\
modulation eff. & $5 \%($ per $100 \mathrm{~cm} \mathrm{OPD})$ \\
phase error & $0.01 \mathrm{rad}$ \\
Line of sight (LOS) & $1^{\prime}$ \\
LT temperature & $2 \mathrm{~K}$ \\
UT temperature & $2 \mathrm{~K}$ \\
line strength, $S$ & $+1 \%$ \\
pres. broad. coef., $\gamma_{\text {air }}$ & $+1 \%$ \\
SDV strength, $\Gamma_{2} / \Gamma_{0}$ & $+5 \%$ \\
\hline
\end{tabular}

Table 2. Estimated random errors of the retrieved $\mathrm{H}_{2} \mathrm{O}$ column abundances for different spectral resolutions: $0.004 \mathrm{~cm}^{-1}$ (typical for NDACC) and $0.02 \mathrm{~cm}^{-1}$ (typical for TCCON).

\begin{tabular}{lcc}
\hline source & Res: $0.004 \mathrm{~cm}^{-1}$ & Res: $0.02 \mathrm{~cm}^{-1}$ \\
\hline spectroscopy & $0.01 \%$ & $<0.01 \%$ \\
measurement noise & $0.08 \%$ & $0.09 \%$ \\
ILS & $0.04 \%$ & $0.03 \%$ \\
temperature (T-fit) & $0.05 \%$ & $0.08 \%$ \\
temperature (no T-fit) & $0.16 \%$ & $0.14 \%$ \\
baseline offset & $0.14 \%$ & $0.14 \%$ \\
LOS (@ 80 $0^{\circ}$ SZA) & $0.17 \%$ & $0.17 \%$ \\
smoothing & $0.57 \%$ & $0.68 \%$ \\
\hline
\end{tabular}

optimal estimation of an absorber profile PROFFIT can estimate temperature profiles. We get the additional temperature information by fitting two spectral microwindows with $\mathrm{CO}_{2}$ lines (at $4720-4735 \mathrm{~cm}^{-1}$ ) simultaneously with the water vapour lines shown in Fig. 2. The simultaneous temperature fit significantly reduces the temperature error (compare solid and dotted cyan lines of Fig. 3). The temperature retrieval is mandatory when analysing very high resolution spectra and when aiming on middle/upper tropospheric water vapour concentrations (see also Schneider et al., 2006).

The systematic profile errors are dominated by uncertainties in the parameters that describe the line shape. Uncertainties in the air broadening parameter $\left(\gamma_{\text {air }}\right)$ are mainly responsible for lower/middle tropospheric errors, whereas an uncertainty in the strength of the speeddependence $\left(\Gamma_{2} / \Gamma_{0}\right)$ mainly affects the middle/upper troposphere (Schneider et al., 2011).

Table 2 collects the estimated random error for the retrieved $\mathrm{H}_{2} \mathrm{O}$ total column abundances. When using the assumptions of Table 1 and performing a simultaneous temperature retrieval only baseline offsets and LOS uncertainties produce errors that are larger than $0.1 \%$. We also list the so-called smoothing error, which is due to the limited vertical resolution of a remote sensing system. Water vapour is
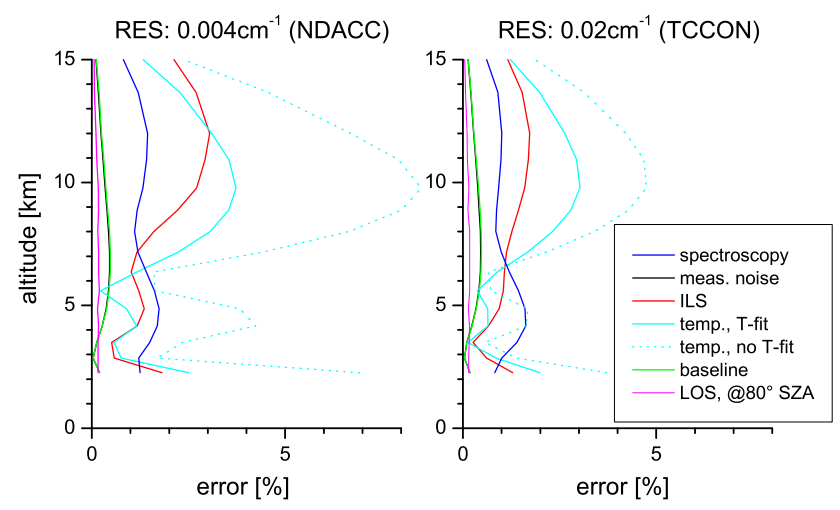

Fig. 3. Estimated $\mathrm{H}_{2} \mathrm{O}$ random profile errors for the profile retrievals of spectra with typical NDACC and TCCON spectral resolution (0.004 and $0.02 \mathrm{~cm}^{-1}$, respectively). Blue: spectroscopic parameters; Black: measurement noise; Red: ILS; Cyan: temperature profile; Green: baseline offset; Magenta: line of sight.
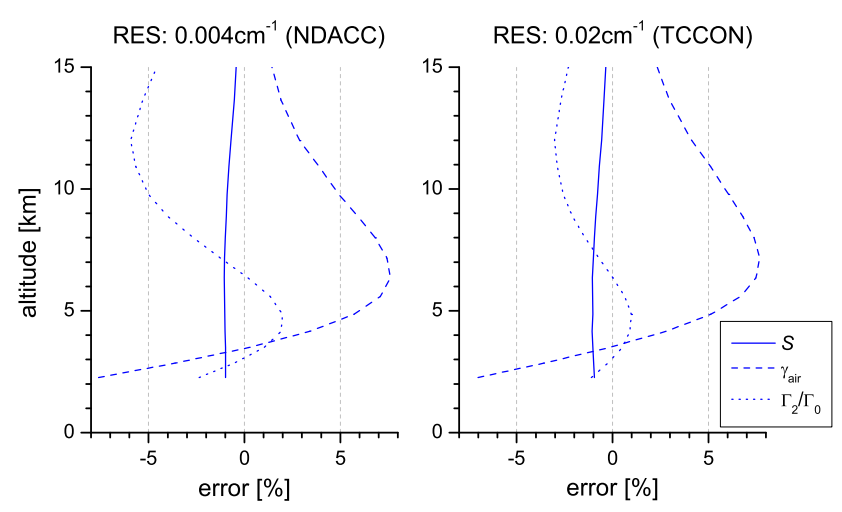

Fig. 4. Same as Fig. 3 but for systematic profile errors. Solid line: line strength $(S)$ uncertainty; Dashed line: pressure broadening coefficient $\left(\gamma_{\text {air }}\right)$ uncertainty; Dotted line: speed-dependence strength $\left(\Gamma_{2} / \Gamma_{0}\right)$ uncertainty.

a extremely variable atmospheric trace gas. Often there are sharp filaments of increased water vapour amounts followed by layers with reduced amounts. The FTIR remote sensing system is not equally sensitive at all atmospheric altitude levels and consequently the highly varying vertical water vapour distributions cause significant random errors in the retrieved column abundances: the smoothing errors.

The smoothing error is larger for the lower resolution TCCON spectra than for the very high resolution NDACC spectra. On the other hand we observe that the retrievals applying very high resolution NDACC spectra have a slightly larger error sensitivity in the middle/upper troposphere than the retrievals applying TCCON spectra (see Figs. 3 and 4). This is due to the fact the retrievals based on the very high resolution spectra are more sensitive to the actual water vapour distribution but at the same time they are also more sensitive to the uncertainty source. 

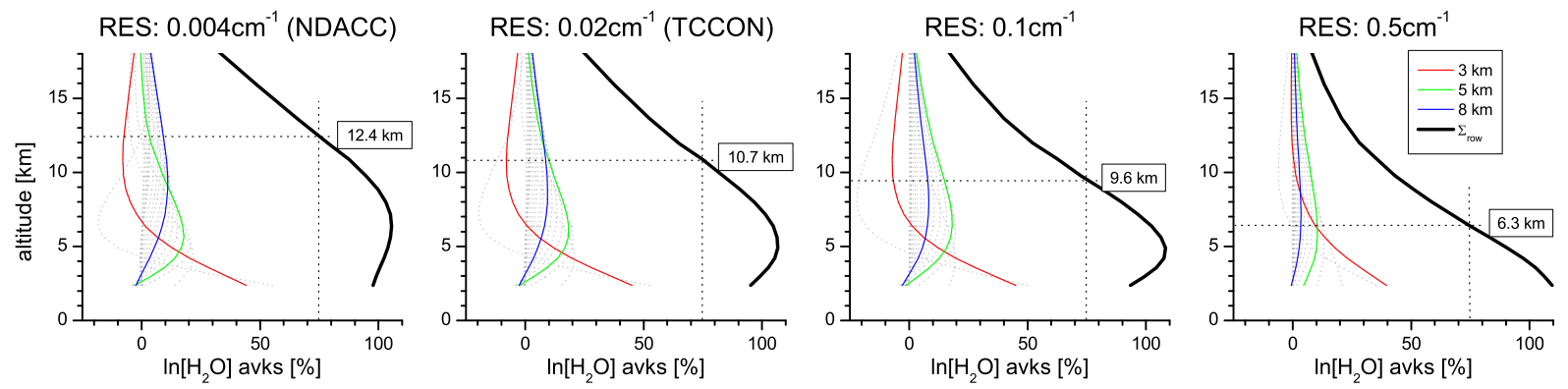

Fig. 5. Averaging kernels for $\ln \left[\mathrm{H}_{2} \mathrm{O}\right]$ for different spectral resolution. From the left to the right: $0.004 \mathrm{~cm}^{-1}, 0.02 \mathrm{~cm}^{-1}$ (resolution of TCCON spectra), $0.1 \mathrm{~cm}^{-1}$, and $0.5 \mathrm{~cm}^{-1}$. Grey lines: kernels for all atmospheric model grid levels; Black, red, and green lines: kernels for the 3,5, and $8 \mathrm{~km}$ grid level (representative for the lower, middle, and upper troposphere), respectively; Thick black line: Sensitivity (sum along the row of the averaging kernel matrix). Indicated is also the altitude where the sensitivity falls below $75 \%$.

It is important to note that ground-based FTIR measurements need clear sky conditions. No measurements can be performed when there is a optically thick cloud cover. This introduces a significant clear sky dry bias in the FTIR data (Schneider et al., 2010a), which has to be considered when interpreting the data.

\section{Vertical resolution versus spectral resolution}

Atmospheric profiles remotely-sensed by ground-based infrared spectrometry offer - compared to in-situ measurements - a limited vertical resolution. The vertical structures that are detectable are documented by the averaging kernels. Figure 5 depicts typical sets of averaging kernels for water vapour profile retrievals when applying the near infrared microwindows of Fig. 2.

In order to assess the effect of spectral resolution on the vertical resolution of the remote sensing system we measured spectra with different spectral resolution $\left(0.004 \mathrm{~cm}^{-1}\right.$, $0.02 \mathrm{~cm}^{-1}, 0.1 \mathrm{~cm}^{-1}$, and $0.5 \mathrm{~cm}^{-1}$ ) during $20 \mathrm{~min}$ on a stable day and for typical conditions (stable typical and water vapour content, solar elevation angles about $35^{\circ}$, typical aerosol loading, etc.).

The averaging kernels for 3,5 , and $8 \mathrm{~km}$ (representative for the lower, middle and upper troposphere) are highlighted by red, blue and green colors, respectively. The sum along the rows of the averaging kernel matrix documents the sensitivity of the remote sensing system. It is depicted as thick black line. For a very high spectral resolution (typical for NDACC measurements) we can detect $3 \mathrm{~km}$ thick layers in the lower troposphere, $6 \mathrm{~km}$ layers in the middle troposphere, and $10 \mathrm{~km}$ layers in the upper troposphere (the layer thickness is defined as the full width at half maximum of the kernels). Then the sensitivity is almost optimal (close to unity) throughout the whole troposphere, which means that the FTIR system is well able to detect the atmospheric variability between the surface and an altitude of about $12.4 \mathrm{~km}$, where still $75 \%$ of the real atmospheric variability can be detected by the remote sensing system. Measuring a high resolution NDACC spectra takes about $8 \mathrm{~min}$.

If we reduce the spectral resolution to $0.02 \mathrm{~cm}^{-1}-$ which is the resolution of TCCON spectra - the middle and upper tropospheric averaging kernels become broader, but on the other hand the measurement time reduces to $2 \mathrm{~min}$. With TCCON spectra lower tropospheric water vapour concentrations can still be well distinguished from middle/upper tropospheric concentrations and we can measure a profile each 2 min. However, then the range with a sensitivity of at least $75 \%$ is limited to altitudes below $10.7 \mathrm{~km}$.

For a spectral resolution of $0.1 \mathrm{~cm}^{-1}$ the measurement time but also the sensitivity range get further reduced, but we still can distinguish water vapour variations that occur above $5 \mathrm{~km}$ altitude from variation close to the surface. If we reduce the spectral resolution to $0.5 \mathrm{~cm}^{-1}$ a measurement takes just a few seconds, but then the system is not well able to separate water vapour variations that occur at different altitudes and it is only satisfactorily sensitive below an altitude of $6.3 \mathrm{~km}$.

The averaging kernels depend on the actual atmospheric water vapour content (level of saturation of the applied water vapour lines). However, we use lines that are typically unsaturated. Even for observations performed at sea level the averaging kernels are similar to the kernels depicted in Fig. 5. As an approximation one can consider the different observer altitudes by vertically shifting the kernels (see also Fig. 1 of Schneider and Hase, 2009).

Ground-based solar absorption spectra contain information about the vertical distribution of the absorber mainly due to the pressure broadening effect (lines are the broader the higher the pressure at the absorbers location). The broadening coefficients are typically $0.04-0.08 \mathrm{~cm}^{-1} \mathrm{~atm}^{-1}$. In the stratosphere, e.g., at $25 \mathrm{~km}$, the pressure is about $0.025 \mathrm{~atm}$ and the frequency of the absorptions that take place in the stratosphere are very well defined. In order to detect the pressure broadening effect in the stratosphere very highlyresolved spectra - like those measured within the NDACC (typical resolution of $0.004 \mathrm{~cm}^{-1}$ ) - are mandatory. In the 


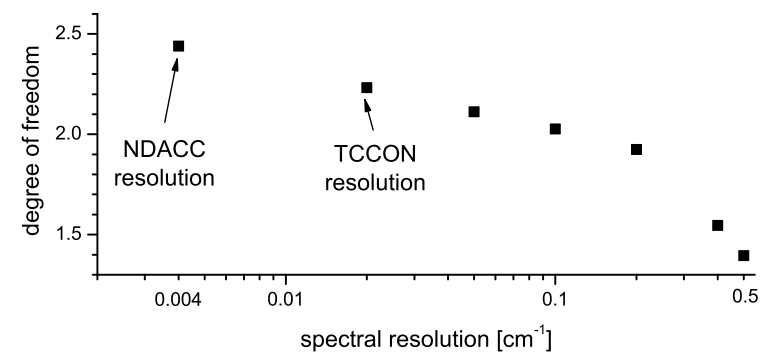

Fig. 6. Degree of freedom of the measurement (dof value) versus spectral resolution.

troposphere the pressure is more than an order of magnitude higher (e.g., it is still about $0.2 \mathrm{~atm}$ at $12 \mathrm{~km}$ ). For a retrieval of tropospheric profiles a spectral resolution of $0.02 \mathrm{~cm}^{-1}$ (or even $0.1 \mathrm{~cm}^{-1}$, see Fig. 5) is obviously sufficient. Naturally, a very high spectral resolution is also advantageous when estimating tropospheric profiles. The higher the spectral resolution the larger the amount of information about the absorbers vertical tropospheric distribution. For this reason the smoothing error is the smaller the higher the resolution of the applied spectra (see Table 2).

The degree of freedom of the measurement (dof value) is a measure of the amount of information that is introduced by the measurement. Figure 6 shows how the dof value depends on the spectral resolution. It is about 2.5 for high resolution spectra, 2.3 for TCCON spectra, and about 2 for $0.1 \mathrm{~cm}^{-1}$ spectral resolution, which seems to be the limit for identifying two independent atmospheric layers. For a poorer spectral resolution the dof value is below 2 and the profiling capability of the system is limited. The TCCON resolution is a good compromise enabling both, good vertical resolution and high measurement frequency.

Please note that the near infrared spectra allow a retrieval of $\mathrm{H}_{2} \mathrm{O}$ profiles but not of $\mathrm{HDO}$ profiles. Above $3000 \mathrm{~cm}^{-1}$ the signatures of the latter are rather weak. $\mathrm{HDO} / \mathrm{H}_{2} \mathrm{O}$ profiles, which are very useful for investigating the atmospheric water cycle (e.g., Worden et al., 2007; Frankenberg et al., 2009; Schneider et al., 2010b), can only be remotely-sensed from ground applying NDACC's mid-infrared spectra but not TCCON's near infrared spectra.

\section{Empirical validation}

In this Section we empirically prove TCCON's water vapour profiling capability, whereby we take Izaña's TCCON measurements as an example. First, we document that the measured water vapour absorption signatures contain significant information about the vertical distribution of tropospheric water vapour. And second, we compare the retrieved water vapour profiles to all in-situ Vaisala RS92 radiosonde profiles measured in coincidence.

\subsection{Absorption signatures and vertical distribution of $\mathrm{H}_{2} \mathrm{O}$}

At Tenerife Island radiosondes (Vaisala RS92) are launched twice per day (11:15 and 23:15 UT). The launch site is just about $15 \mathrm{~km}$ southeast of the Observatory on the coastline. The radiosonde measurements offer a good opportunity for documenting the FTIR's $\mathrm{H}_{2} \mathrm{O}$ profiling capability (e.g. Schneider et al., 2010a). Figure 7 shows some examples for the agreement between radiosonde and FTIR profiles measured in coincidence. The small black squares show the RS92 profiles after correction of temperature effects and radiation bias (Vömel et al., 2007). These in-situ profiles offer a very high vertical resolution. In contrast, the remote sensing technique only allows resolving rather rough vertical structures (see averaging kernels of Fig. 5). For an adequate comparison we have to degrade the RS92 profiles to the vertical resolution of the FTIR profiles (e.g., Schneider et al., 2010a). The blue stars in Fig. 7 depict the RS92 profiles with the vertical resolution adjusted to the the FTIR profiles and the red circles depict the optimally estimated FTIR profiles. The profiles are shown as relative difference to the climatologic profile that is applied as the a priori. Any difference to the $0 \%$ line is produced by the FTIR measurement. For the coincidences shown in Fig. 7, FTIR and smoothed RS92 profiles detect very similar differences to the a priori profile, which documents the good quality of the FTIR data.

In addition Fig. 7 depicts the profiles produced by an retrieval setup that only allows for a scaling of the a priori profile (thick green dashed line). This retrieval approach postulates that the absorption signatures contain information about the total column abundances of the absorber but not of its vertical distribution. Naturally, if the actual atmosphere contains vertical water vapour structures which are similar to the a priori situation (slope of the actual profile is similar to the slope of the a priori profile) the scaled profile and the optimally estimated profile are similar. This is the case on the days 090124 and 100609. However, if the actual profile slope is significantly different from the a priori profile slope (days 090125 and 100611) the scaled profile and the optimally estimated profile differ significantly.

Figure 8 shows the residuals between measured and simulated spectra for the four exemplary measurements presented in Fig. 7. Here we take the $4609.9-4612.25 \mathrm{~cm}^{-1}$ spectral window as example. If the actual vertical $\mathrm{H}_{2} \mathrm{O}$ structures significantly differ from the climatologic mean situation (day 090125 and 100611) the spectral residuals produced by the scaling retrievals are much larger than the residuals produced by the profile optimal estimation retrieval. On day 090125 the scaling approach produces a spectral residual of $0.53 \%$ (expressed as the root-mean-squares value: rms). We observe that the synthetic spectra does not well simulate the measured absorption signature. To the contrary the rms value corresponding to the profile optimal estimation approach is only $0.21 \%$. For this approach the simulated and the measured 

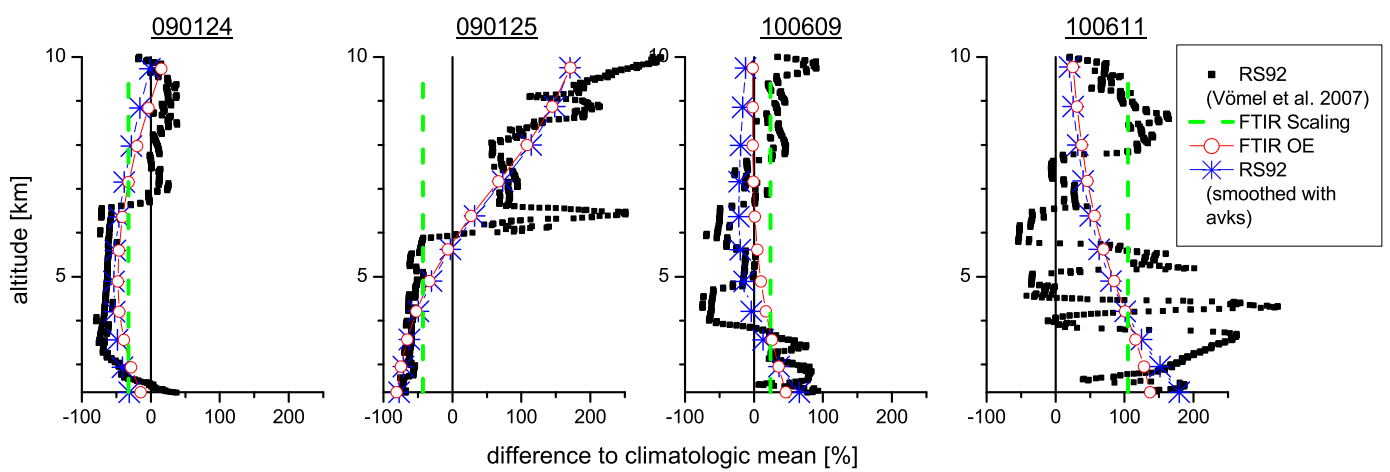

Fig. 7. Examples for coincident Vaisala RS92 and FTIR $\mathrm{H}_{2} \mathrm{O}$ measurements (scaling and OE approach). Presented as percentage difference to a subtropical climatologic profile. Black squares: RS92 data corrected by the Vömel et al. (2007) method; Green dashed line: FTIR scaling approach; Red circles: FTIR OE approach; Blue stars: RS92 smoothed with FTIR averaging kernels.
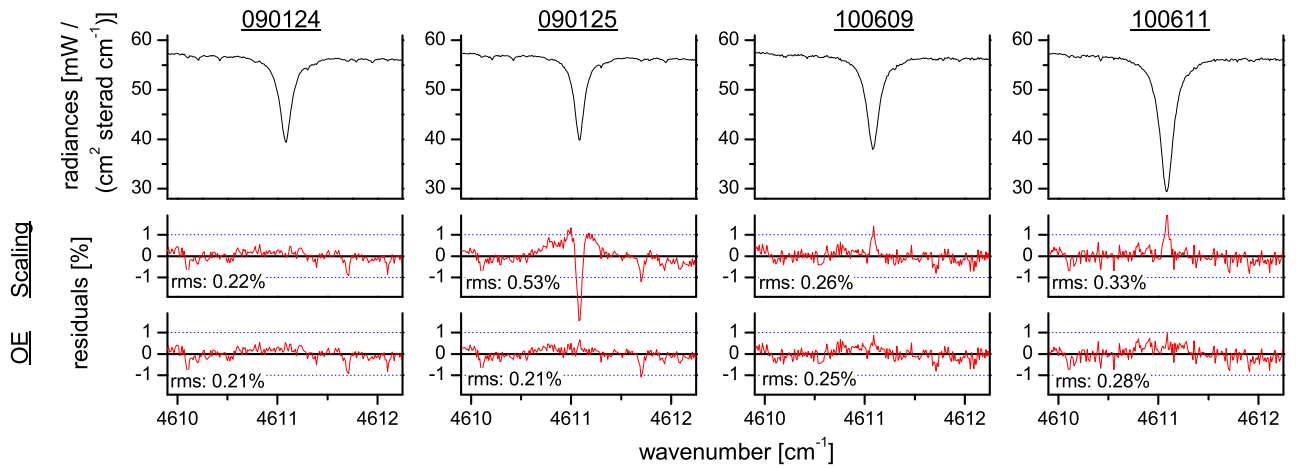

Fig. 8. Measured spectra and residuals of the $4609.9-4612.25 \mathrm{~cm}^{-1}$ spectral window corresponding to the four examples of Fig. 7. Top panels: measured spectra; Middle panels: residuals for scaling approach; Bottom panel: residuals for OE approach. The root-mean-squares (rms) values of the residuals are given in each panel.

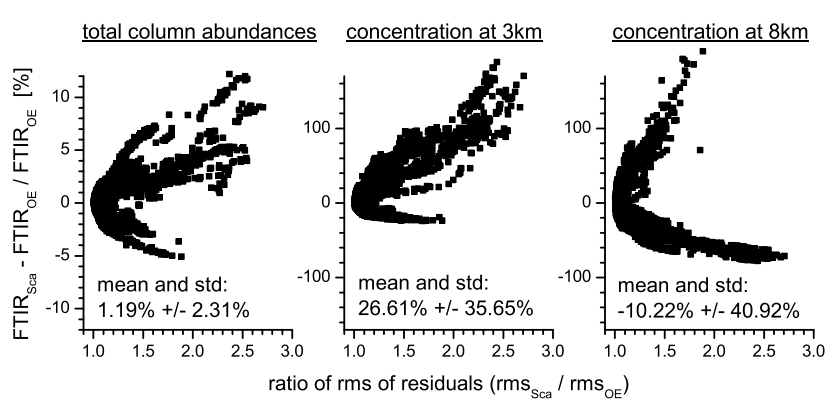

Fig. 9. Difference between $\mathrm{H}_{2} \mathrm{O}$ total column amounts and lower and middle/upper tropospheric concentrations obtained by the FTIR scaling (Sca) and profile optimal estimation (OE) approach versus the rms value of the respective residuals.

spectra are in very good agreement. The increased spectral residuals produced by the scaling retrieval documents that the spectra contain a lot of information about the vertical distribution of the absorber.
Figure 9 expands the findings of Figs. 7 and 8 to the more than 3000 Izaña near-infrared spectra that have been measured since June 2008 (when we started recording AC and DC signals in the near-infrared). The Figure shows a comparison of the $\mathrm{H}_{2} \mathrm{O}$ data retrieved by the scaling and the optimal estimation approach versus the ratio of the respective spectral residuals. The vertical distribution of water vapour is highly-variable and we observe that a situation like on day 091025 or 100611 is rather frequent: for about $50 \%$ of all measurements the scaling retrieval produces residuals that are at least by $20 \%$ larger than the residuals produced by the optimal estimation approach. The increased residuals of the scaling retrievals document that the TCCON spectra contain significant information about the vertical distribution of tropospheric water vapour. Figure 9 documents that the high variability of the vertical distribution of water vapour is well reflected in the water vapour absorption signatures and that the FTIR system is well able to distinguish lower from middle/upper tropospheric water vapour amounts. 

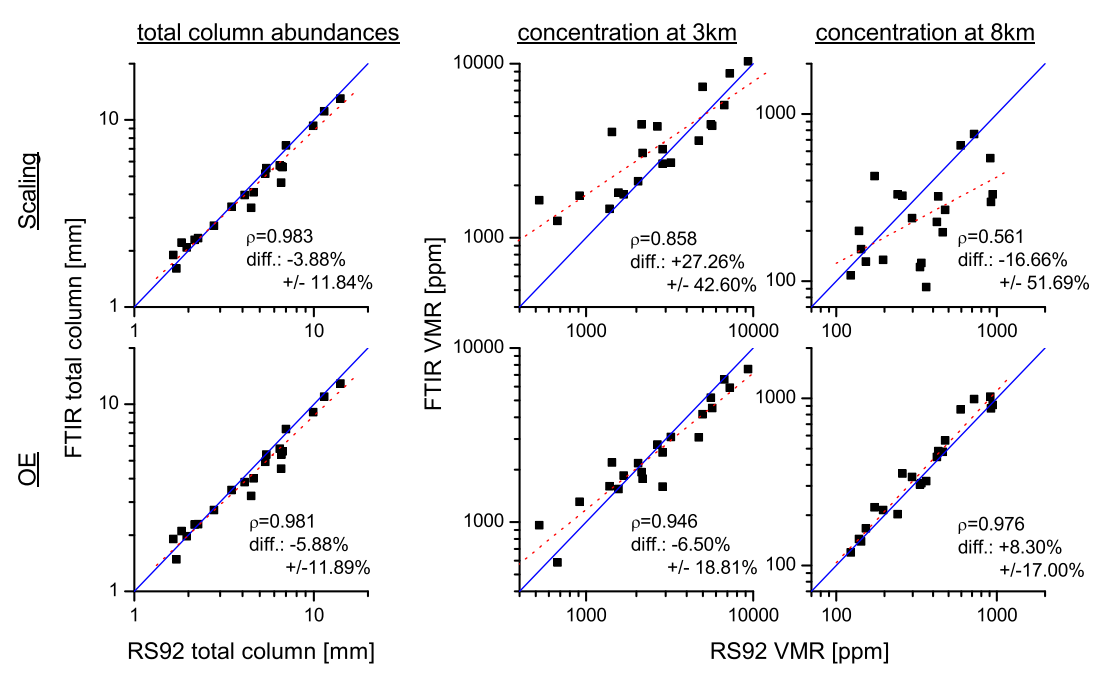

Fig. 10. Correlation between column amounts and volume mixing ratios obtained from coincident Vaisala RS92 and FTIR $\mathrm{H}_{2} \mathrm{O}$ measurements (Upper panels for scaling and bottom panels for OE approach). From left to right: total column abundances, volume mixing ratios at $3 \mathrm{~km}$ and $8 \mathrm{~km}$. Blue solid lines: diagonals; Red dotted lines: linear regression lines.

\subsection{Correlation between coincident FTIR and RS92 measurements}

Between June 2008 and August 2010, there are 21 very close coincidences between the Vaisala RS92 and FTIR nearinfrared measurements (including the four situations shown in Fig. 7). As close coincidence we define the situation that the radiosonde measures at $3 \mathrm{~km}$ within $10 \mathrm{~min}$ of the FTIR near-infrared measurement (which takes about $2 \mathrm{~min}$ ). Figure 10 shows correlations between the water vapour data measured by the RS92 and the FTIR system: the upper panels for the scaling retrieval and the bottom panels for the profile optimal estimation retrieval. The left panels depict total column abundances, the central panels concentrations at $3 \mathrm{~km}$ and the right panels concentrations at $8 \mathrm{~km}$ (whereby RS92 data have been smoothed with the FTIR kernels obtained from the profile optimal estimation retrieval).

Naturally the data produced by the scaling approach do not well correlate with the RS92 profile. On the other hand, the optimal estimation approach produces middle/upper tropospheric $\mathrm{H}_{2} \mathrm{O}$ concentrations which very nicely agree with the RS92 concentrations (see bottom right panel: correlation coefficient $\rho$ of 0.976 at $8 \mathrm{~km}$ ). In the lower troposphere (see bottom middle panel) the correlation is weaker ( $\rho$ of 0.946 at $3 \mathrm{~km}$ ), since both experiments detect very likely a different lower tropospheric airmass: the RS92 is launched from the coastline, $15 \mathrm{~km}$ southeast of the observatory. When reaching the altitude of the FTIR instrument ( $2370 \mathrm{~m}$ a.s.l.) it is floating in the free troposphere at a significant distance from any landmass. In contrast the water vapour amounts detected by the FTIR instrument will certainly be affected by the landmass (turbulent processes, latent heat transfer, etc.). Therefore, lower tropospheric and total column $\mathrm{H}_{2} \mathrm{O}$ abundances detected by the RS92 and the FTIR are hardly comparable.

For more extensive FTIR-RS92 inter-comparison studies at different sites and applying different spectral signatures please refer to Schneider et al. (2010a) and Schneider et al. (2010c).

\section{Time scale analysis}

Spectra with a resolution of $0.02 \mathrm{~cm}^{-1}$ are measured in less than $2 \mathrm{~min}$. TCCON can provide a uniquely dense set of solar absorption spectra. Applying the optimal estimation approach we can use the TCCON measurements for investigating variations in the tropospheric water vapour distribution on different timescales ranging from a few minutes up to several days. Figure 11 shows an example of a diurnal evolution of lower and upper tropospheric $\mathrm{H}_{2} \mathrm{O}$ concentration as obtained from TCCON measurements at Izaña. Shown is the difference to the climatologic mean $\left(\frac{\hat{x}-x_{a}}{x_{a}}\right.$, whereby $\hat{x}$ represents the retrieved water vapour concentrations and $x_{a}$ the a priori climatologic mean). On this day we measured about 90 near infrared spectra between 12:30 and 16:30 UT. The black and red error bars on the right side of the plot indicate the total random errors as estimated in Sect. 3.

Concerning the lower troposphere at $3 \mathrm{~km}$ we observe rather large short-term variability between 12:30 and 14:30 UT. This variability is much larger than the estimated random error (compare the black error bar with the short timescale scatter of the black squares before 14:30 UT). This variability is due to increased turbulence during the morning hours when the landmass heats faster than the overlying airmass, thereby producing an instable atmospheric layering. The vertical instabilities efficiently increase the water vapour amounts and adiabatically cool the lower/middle 


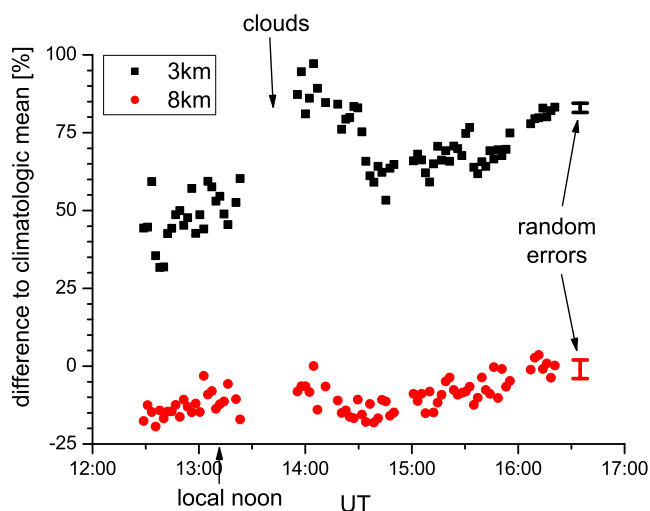

Fig. 11. Evolution of lower (black squares) and middle/upper (red dots) water vapour concentrations between 12:30 and 16:30 UT on the 19 May 2010. The error bars indicate total random errors as estimated for the respective altitudes (see right panel of Fig. 3).

troposphere. As a consequence between 13:30 and 14:00 UT the lower/middle troposphere above Izaña gets saturated and the water partly condensates to cloud droplets. The situation is different at the end of the day. Then the landmass cools faster than the overlying airmass thereby causing high vertical stability. After 15:30 UT the low short-term variability can fully be explained by the estimated random error.

In the upper troposphere the diurnal evolution is rather smooth. There the water vapour concentrations are rather constant during the whole day. The observed short-term variability can fully be explained by the random error (compare scatter of red dots with red error bar).

We find that such increased lower tropospheric shortterm variability is a typical situation. Figure 12 plots profiles of the tropospheric water vapour variability on different timescales as obtained from TCCON measurements. The study bases on measurements taken at Izaña on 57 different days between June 2008 and August 2010. On 15 of these days we measured continuously near-infrared spectra for at least $2 \mathrm{~h}$ allowing 50-100 individual profile retrievals for each of these days. We define the variability as the $1 \sigma$ standard deviation of the difference to the a priori value. We observe that most variability occurs on timescales that are larger than 1 day. However, even on very short timescales lower tropospheric variabilities cannot be neglected. Within $15 \mathrm{~min}$ only, lower tropospheric water vapour already varies by $6 \%$, which is clearly larger than the estimated measurement uncertainty (dotted grey line). The significant variability on rather short timescales justifies the strict coincidence criterion applied for the comparison shown in Figs. 7 and 10. The short timescale variability also points to small-scale structures in the horizontal water vapour fields of the lower troposphere. The significant small-scale and short timescale variability converts the inter-comparison of lower tropospheric water vapour measurement techniques into a difficult task.

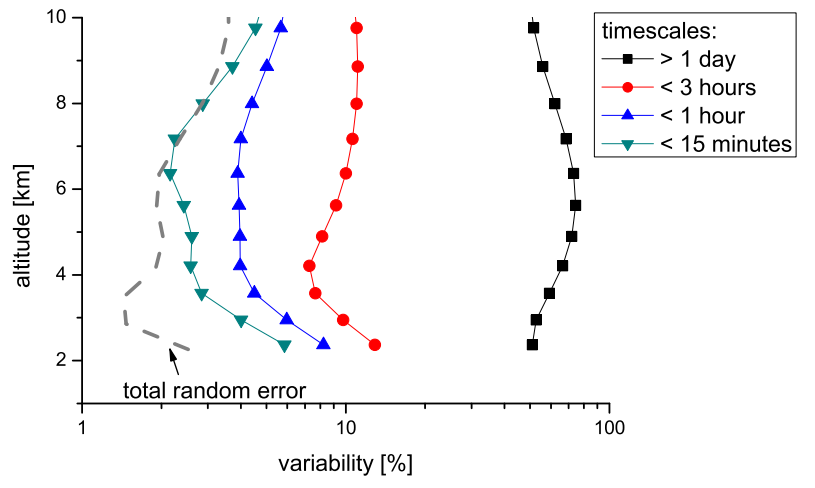

Fig. 12. Water vapour variability for the different timescales as indicated in the legend. The dotted grey line indicates the estimated total random error (see right panel of Fig. 3).

It is strongly recommendable that the different techniques measure at exactly the same time and at the same place. Detecting a slightly different airmass can introduce significant uncertainties in the inter-comparison study.

The situation is a bit less critical in the middle/upper troposphere, where a variability of larger than $6 \%$ is only observed for timescales larger than $1 \mathrm{~h}$. It seems that the middle/upper troposphere is more stable and changes are smoother in time as well as in space.

It should be noted that the lower tropospheric water vapour structure can also be observed at very high temporal resolution using ground-based atmospheric emission measurements in the infrared and microwave region (Smith et al., 1999; Güldner and Spänkuch, 2001). However, to our knowledge and concerning middle/upper tropospheric water vapour only TCCON can provide a temporally dense data set with good quality.

\section{Conclusions}

TCCON is a rather new and expensive network of high quality ground-based FTIR systems. There has been a lot of effort for guaranteeing an ultimate quality of the measured spectra. TCCON's high quality standards as well as its long-term strategy are very attractive for many fields of atmospheric research, in particular for climate change research. Understanding the atmospheric water vapour distribution is very important for understanding Earth's climate. We show that the TCCON measurements can be used to monitor tropospheric water vapour profiles with a vertical resolution of 3 and $8 \mathrm{~km}$ in the lower and middle/upper troposphere, respectively. As long as one does not aim for an ultimate sensitivity in the upper troposphere it is not necessary to record additional spectra with higher resolution. The TCCON resolution is sufficient and can provide data at a very high measurement frequency (one measurement every 1-2 min). 
The density of the TCCON $\mathrm{H}_{2} \mathrm{O}$ profile data will allow an analysis of tropospheric water vapour variability for different altitudes and on different timescales ranging from several hours to a few minutes. This is important for assessing the validity and limits of water vapour profile inter-comparison studies. Furthermore, it might allow novel studies of short timescale processes thereby leading to an improved parameterisation and thus model representation of turbulence, convection, or lateral mixing processes.

Acknowledgements. M. Schneider was supported by the Deutsche Forschungsgemeinschaft via the project RISOTO (Geschäftszeichen SCHN 1126/1-1 and 1-2) and since May 2010 he has enjoyed a Ramón y Cajal grant from the Spanish Ministry of Science and Innovation. E. Sepúlveda receives a predoctoral fellowship from the Spanish Ministry of Education. The establishment of TCCON was generously supported by grants from NASA's terrestrial carbon cycle program and from the OCO project office. We are grateful to the Goddard Space Flight Center for providing the temperature and pressure profiles of the National Centers for Environmental Prediction via the automailer system.

Edited by: B. Funke

\section{References}

Abrams, M. C., Toon, G. C., and Schindler, R. A. : Practical example of the correction of Fourier-transform spectra for detector nonlinearity, Appl. Optics, 33(27), 6307-6314, doi:10.1364/AO.33.006307, 1994.

Frankenberg, C., Yoshimura, K., Warneke, T., Aben, I., Butz, A., Deutscher, N., Griffith, D., Hase, F., Notholt, J., Schneider, M., Schrejver, H., and Röckmann, T.: Dynamic processes governing lower-tropospheric $\mathrm{HDO} / \mathrm{H}_{2} \mathrm{O}$ ratios as observed from space and ground, Science, doi:10.1126/science.1173791, 325, 13741377, 2009.

Geibel, M. C., Gerbig, C., and Feist, D. G.: A new fully automated FTIR system for total column measurements of greenhouse gases, Atmos. Meas. Tech., 3, 1363-1375, doi:10.5194/amt-31363-2010, 2010.

Gisi, M., Hase, F., Dohe, S., and Blumenstock, T.: Camtracker: a new camera controlled high precision solar tracker system for FTIR-spectrometers, Atmos. Meas. Tech. Discuss., 3, 48654887, doi:10.5194/amtd-3-4865-2010, 2010.

Güldner, J. and Spänkuch, D.: Remote sensing of the thermodynamic state of the atmospheric boundary layer by ground-based microwave radiometry, J. Atmos. Ocean. Technol., 18, 925-933, 2001.

Hase, F., Blumenstock, T., and Paton-Walsh, C.: Analysis of the instrumental line shape of high-resolution Fourier transform IR spectrometers with gas cell measurements and new retrieval software, Appl. Opt., 38, 3417-3422, 1999.

Hase, F. and Höpfner, M.: Atmospheric raypath modelling for radiative transfer algorithms, Appl. Opt., 38, 3129-3133, 1999.

Hase, F., Hannigan, J. W., Coffey, M. T., Goldman, A., Höpfner, M., Jones, N. B., Rinsland, C. P., and Wood, S. W.: Intercomparison of retrieval codes used for the analysis of high-resolution, ground-based FTIR measurements, J. Quant. Spectrosc. Ra., 87, 25-52, 2004.

Keppel-Aleks, G., Toon, G. C., Wennberg, P. O., and Deutscher, N. M.: Reducing the impact of source brightness fluctuations on spectra obtained by Fourier-transform spectrometry, Appl. Opt., 46, 4774-4779, 2007.

Kurylo, M. J. and Zander, R.: The NDSC - Its status after 10 years of operation, Proceedings of XIX Quadrennial Ozone Symposium, Hokkaido University, Sapporo, Japan, 167-168, 2000.

Messerschmidt, J., Macatangay, R., Notholt, J., Petri, C., Warneke, T., and Weinzierl, C.: Side by side measurements of $\mathrm{CO}_{2}$ by ground-based Fourier transform spectrometry (FTS), Tellus B, 62, 749-758, 2010.

Olsen, S. C., and Randerson, J. T.: Differences between surface and column atmospheric $\mathrm{CO}_{2}$ and implications for carbon cycle research, J. Geophys. Res., 109, D02301, doi:10.1029/2003JD003968, 2004.

Randall, D. A., Wood, R. A., Bony, S., Colman, R., Fichefet, T., Fyfe, J., Kattsov, V., Pitman, A., Shukla, J., Srinivasan, J., Stouffer, R. J., Sumi, A., and Taylor, K. E.: Climate Models and Their Evaluation, in: Climate Change 2007: The Physical Science Basis, Contribution of Working Group I to the Fourth Assessment Report of the Intergovernmental Panel on Climate Change, edited by: Solomon, S., Qin, D., Manning, M., Chen, Z., Marquis, M., Averyt, K. B., Tignor, M., and Miller, H. L., Cambridge University Press, Cambridge, United Kingdom and New York, NY, USA, 2007.

Rodgers, C. D.: Inverse Methods for Atmospheric Sounding: Theory and Praxis, World Scientific Publishing Co., Singapore, ISBN 981-02-2740-X, 2000.

Rothman, L. S., Gordon, I. E., Barbe, A., Chris Benner, D., Bernath, P. F., Birk, M., Boudon, V., Brown, L. R., Campargue, A., Champion, J.-P., Chance, K., Coudert, L. H., Dana, V., Devi, V. M., Fally, S., Flaud, J.-M., Gamache, R. R., Goldman, A. Jacquemart, D., Kleiner, I., Lacome, N., Lafferty, W. J., Mandin, J.-Y., Massie, S. T., Mikhailenko, S. N., Miller, C. E., Moazzen-Ahmadi, N., Naumenko, O. V., Nikitin, A. V., Orphal, J., Perevalov, V. I., Perrin, A., Predoi-Cross, A., Rinsland, C. P., Rotger, M., Simecková, M., Smith, M. A. H., Sung, K., Tashkun, S. A., Tennyson, J., Toth, R. A., Vandaele, A. C., and Vander-Auwera, J.: The HITRAN 2008 molecular spectroscopic database, J. Quant. Spectrosc. Radiat. Transfer, 110, 533-572, doi:10.1016/j.jqsrt.2009.02.013, 2009.

Schneider, M., Hase, F., and Blumenstock, T.: Water vapour profiles by ground-based FTIR spectroscopy: study for an optimised retrieval and its validation, Atmos. Chem. Phys., 6, 811-830, doi:10.5194/acp-6-811-2006, 2006.

Schneider, M. and Hase, F.: Ground-based FTIR water vapour profile analyses, Atmos. Meas. Tech., 2, 609-619, doi:10.5194/amt2-609-2009, 2009.

Schneider, M., Romero, P. M., Hase, F., Blumenstock, T., Cuevas, E., and Ramos, R.: Continuous quality assessment of atmospheric water vapour measurement techniques: FTIR, Cimel, MFRSR, GPS, and Vaisala RS92, Atmos. Meas. Tech., 3, 323338, doi:10.5194/amt-3-323-2010, 2010a.

Schneider, M., Yoshimura, K., Hase, F., and Blumenstock, T.: The ground-based FTIR network's potential for investigating the atmospheric water cycle, Atmos. Chem. Phys., 10, 3427-3442, doi:10.5194/acp-10-3427-2010, 2010 b. 
Schneider, M., Toon, G. C., Blavier, J.-F., Hase, F., and Leblanc, T.: $\mathrm{H}_{2} \mathrm{O}$ and $\delta \mathrm{D}$ profiles remotely-sensed from ground in different spectral infrared regions, Atmos. Meas. Tech., 3, 1599-1613, doi:10.5194/amt-3-1599-2010, 2010c.

Schneider, M., Hase, F., Blavier, J.-F., Toon, G. C., and Leblanc, T.: An empirical study on the importance of a speed-dependent Voigt line shape model for tropospheric water vapor profile remote sensing, J. Quant. Spectrosc. Radiat. Transfer, 112, 465474, doi:10.1016/j.jqsrt.2010.09.008, 2011.

Sherwood, S. C., Ingram, W., Tsushima, Y., Satoh, M., Roberts, M., Vidale, P. L., and O'Gorman, P. A.: Relative humidity changes in a warmer climate, J. Geophys. Res., 115, D09104, doi:10.1029/2009JD012585, 2010.

Smith, W. L., Feltz, W. F., Knuteson, R. O., Revercomb, H. E., Woolf, H. M., and Howell, H. B.: The Retrieval of Planetary Boundary Layer Structure Using Ground-Based Infrared Spectral Radiance Measurements, J. Atmos. Ocean. Technol., 16, 323-333, 1999.

Spencer, R. W. and Braswell, W. D.: How Dry is the Tropical Free Troposphere?, Implications for Global Warming Theory, B. Am. Meteor. Soc., 78, 1097-1106, 1997.

Vömel, H., Selkirk, H., Miloshevich, L., Valverde, J., Valdés, J., Kyrö, E., Kivi, R., Stolz, W., Peng, G., and Diaz, J. A.: Radiation dry bias of the Vaisala RS92 humidity sensor, J. Atmos. Oceanic Technol., 24, 953-963, 2007.

Wagner G. and Birk, M.: Water spectroscopy in the $1 \mu \mathrm{m}$ region - a case study for collisional narrowing, 64th International Meeting on Molecular Spectroscopy, Columbus, Ohio, USA, 22-26 June, 2009.

Washenfelder, R. A., Toon, G. C., Blavier, J.-F., Yang, Z., Allen, N. T., Wennberg, P. O., Vay, S. A., Matross, D. M., and Daube, B. C.: Carbon dioxide column abundances at the Wisconsin Tall Tower site, J. Geophys. Res., 111, D22305, doi:10.1029/2006JD007154, 2006.
Worden, J. R., Noone, D., Bowman, K., Beer, R., Eldering, A., Fisher, B., Gunson, M., Goldman, A., Herman, R., Kulawik, S. S., Lampel, M., Osterman, G., Rinsland, C., Rodgers, C., Sander, S., Shephard, M., Webster, C. R., and Worden, H.: Importance of rain evaporation and continental convection in the tropical water cycle, Nature, 445, 528-532, doi:10.1038/nature05508, 2007.

Wunch, D., Toon, G. C., Blavier, J.-F., Washenfelder, R., Notholt, J., Connor, B. J., Griffith, D. W. T., Sherlock, V., and Wennberg, P. O.: The Total Carbon Column Observing Network (TCCON), Philos. T. R. Soc. A, accepted, 2010a.

Wunch, D., Toon, G. C., Wennberg, P. O., Wofsy, S. C., Stephens, B. B., Fischer, M. L., Uchino, O., Abshire, J. B., Bernath, P., Biraud, S. C., Blavier, J.-F. L., Boone, C., Bowman, K. P., Browell, E. V., Campos, T., Connor, B. J., Daube, B. C., Deutscher, N. M., Diao, M., Elkins, J. W., Gerbig, C., Gottlieb, E., Griffith, D. W. T., Hurst, D. F., Jimnez, R., Keppel-Aleks, G., Kort, E. A., Macatangay, R., Machida, T., Matsueda, H., Moore, F., Morino, I., Park, S., Robinson, J., Roehl, C. M., Sawa, Y., Sherlock, V., Sweeney, C., Tanaka, T., and Zondlo, M. A.: Calibration of the Total Carbon Column Observing Network using aircraft profile data, Atmos. Meas. Tech., 3, 1351-1362, doi:10.5194/amt-31351-2010, 2010b.

Yang, Z., Toon, G. C., Margolis, J. S., and Wennberg, P. O.: Atmospheric $\mathrm{CO}_{2}$ retrieved from ground-based near IR solar spectra, Geophys. Res. Lett., 29, 1339, doi:10.1029/2001GL014537, 2002. 